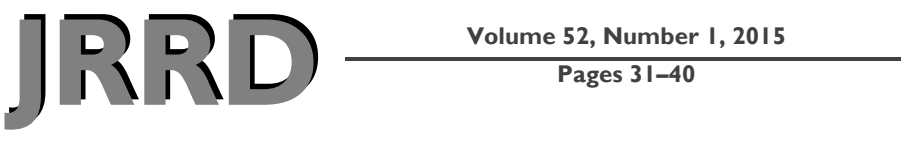

\title{
Incidence, severity, and impact of hyperhidrosis in people with lower- limb amputation
}

\author{
Colby Hansen, MD; ${ }^{1 *}$ Bradeigh Godfrey, DO; ${ }^{1-2}$ Jody Wixom, MD; ${ }^{1,3}$ Molly McFadden, MS ${ }^{4}$ \\ ${ }^{1}$ Division of Physical Medicine and Rehabilitation, University of Utah School of Medicine, Salt Lake City, UT; ${ }^{2}$ George \\ E. Wahlen Department of Veterans Affairs (VA) Medical Center, VA Salt Lake City Health Care System, Salt Lake City, \\ UT; ${ }^{3}$ Physical Medicine and Rehabilitation, Utah Valley Regional Medical Center, Provo, UT; ${ }^{4}$ Division of Epidemiology, \\ University of Utah, Salt Lake City, UT
}

\begin{abstract}
To assess the incidence and severity of selfreported hyperhidrosis in patients with amputation and understand its effects on prosthetic fit or function, a cross-sectional survey of patients at two amputee clinics was performed. Responses from 121 subjects with lower-limb amputation were analyzed. Of these subjects, $66 \%$ reported sweating to a degree that it interfered with daily activities, as measured by the Hyperhidrosis Disease Severity Scale. There was a significant association between sweating and interference with prosthetic fit and function. Sweating was more severe in cases of transtibial amputations, patients under the age of $60 \mathrm{yr}$, warm weather, and vigorous activity. There was no relationship between severity of sweating and time since amputation, etiology of amputation, duration of daily prosthetic use, or reported ability to perform functional tasks. Subjects reported trying multiple interventions, but the self-reported effectiveness of these treatments was low. Hyperhidrosis, a common problem associated with prosthetic usage, varies in severity and often interferes with daily activities. Sweating severity is associated with poor prosthetic fit and function. Risk factors include younger age and transtibial amputation status. Treatment strategies generally lack efficacy. The results of this study may provide guidance for future interventions and treatment options.
\end{abstract}

Key words: amputation, amputee, artificial limb, cross-sectional survey, hyperhidrosis, prosthesis, rehabilitation, skin, survey, sweating.

\section{INTRODUCTION}

The number of persons living with limb loss continues to climb, from 1.6 million people living with amputation in the United States in 2005 to up to 3 million anticipated by 2050 [1]. Quality of life for people with amputation is partly dependent on the successful use of a prosthetic device [2-4]. The skin-socket interface plays a vital role in determining this success, and residual-limb skin problems have been shown to have a negative effect on prosthetic use [5] and ability to perform activities of daily living (ADLs) [6], as well as quality of life [7]. Excessive sweating, or hyperhidrosis, was the single most reported skin problem in a survey of people with lower-limb amputation [8]; the overall incidence has been estimated at 66 percent [9]. Heat and sweating have been identified as the most frequent amputee problem leading to a reduced quality of life, even more so than pain [10]. In a group of people with upper-limb amputation, excessive sweating was identified as the most

\footnotetext{
Abbreviations: $\mathrm{ADL}=$ activity of daily living, $\mathrm{ANOVA}=$ analysis of variance, HDSS = Hyperhidrosis Disease Severity Scale, LCI-5 = Locomotor Capabilities Index 5.

*Address all correspondence to Colby R. Hansen, MD; 30 N 1900 E, Salt Lake City, UT 84132; 801-581-2932; fax: 801-587-9466. Email: Colby.hansen@hsc.utah.edu http://dx.doi.org/10.1682/JRRD.2014.04.0108
} 
frequent reason for not wearing a prosthesis [11]. Hyperhidrosis has also been identified as an inciting factor leading to other skin problems, such as infection, contact dermatitis, and skin lesions [7,12-13].

Despite the frequency and impact of excessive sweating in people with amputation, there is a lack of evidence-based guidance for clinicians faced with treating this issue. Clinicians may suggest trying various liners or socket designs [14-18], topical antiperspirants, or botulinum toxin injections [19-20]. Although hyperhidrosis is identified as a common and significant concern, no literature specifically characterizes this problem in people with amputation. To effectively manage and treat this challenge, there must be better understanding of its incidence and effect on this population.

The objective of this study was to better understand the incidence and effect of hyperhidrosis on people with amputation and their quality of life, including the effect on prosthetic fit and function and methods that people with amputation have used to address the problem. This study utilized the Hyperhidrosis Disease Severity Scale (HDSS) (Table 1), a qualitative scale that allows tailoring of treatment based on patient-identified severity and effect on daily activities [21], as a subjective measure of hyperhidrosis severity and impact. In addition, the study gathered further information about associated factors, available treatments, and effect on prosthetic fit and function.

\section{METHODS}

\section{Participants}

The participants were recruited from among patients who had at least one visit to an outpatient amputee clinic, either at the University of Utah Medical Center or the Department of Veterans Affairs Medical Center in Salt Lake City, Utah. The protocol for this study was approved

Table 1.

Hyperhidrosis Disease Severity Scale [21].

\begin{tabular}{lc}
\hline \multicolumn{1}{c}{ Condition } & Score \\
\hline $\begin{array}{l}\text { My sweating is never noticeable and never inter- } \\
\text { feres with my daily activities }\end{array}$ & 1 \\
My sweating is tolerable but sometimes interferes & 2 \\
$\quad$ with my daily activities & 3 \\
My sweating is barely tolerable and frequently & \\
interferes with my daily activities & 4 \\
My sweating is intolerable and always interferes & 4 \\
with my daily activities & \\
\hline \hline
\end{tabular}

by the Institutional Review Board of the respective institutions and informed consent was obtained from all potential participants as required. Potential participants were mailed surveys or were invited to participate at the time of a clinic visit. The study included participants with single or multiple limb amputations who were at least 6 mo post-amputation surgery with a healed surgical wound and who had a prosthetic limb manufactured for them. The study excluded those with an ankle disarticulation or partial foot amputation.

\section{Survey Description}

We developed a survey to evaluate the participants' self-reported hyperhidrosis using the HDSS and other descriptive characteristics. Participants were asked to identify the severity of sweating in their residual limb based on the HDSS. This 4-point scale is the most commonly used measurement of hyperhidrosis in dermatology, has been validated, and has strong associations with objective measures of sweating (Table 1) [21]. For the purposes of this study, hyperhidrosis was defined as an HDSS score of $\geq 2$. This value was chosen because patients with an HDSS of $\geq 2$ are considered candidates for treatment by dermatology practice guidelines [21].

Descriptive data including age, sex, level of amputation(s), and etiology of amputation were obtained. Participants were asked to identify how many hours per day they wore their prosthesis and whether sweating was bothersome during warm weather and vigorous activity. They were also asked to rate, on a 5-point scale, the extent to which residual-limb sweating was a problem in various seasons of the year, the interference of residuallimb sweating on prosthesis fit and function, and the type and perceived effectiveness of past or current treatments received for hyperhidrosis.

The Locomotor Capabilities Index 5 (LCI-5) was used as a measure of function in the participants with lower-limb amputation. The LCI-5 is a validated and reliable measure of function in people with amputation [2223 ] that can be self-administered; it provides a comprehensive profile of the ambulatory skills of people with lower-limb amputation who use a prosthesis. It consists of 14 questions that identify the level of independence while performing various activities, each graded on a 5point ordinal scale for a total maximum possible score of 56. The patient is asked whether he or she would be able to perform these activities and to grade the amount of assistance he or she would need, ranging from needing 
help from another person to being able to perform the task independently without ambulation aides.

\section{Statistical Analysis}

Descriptive statistics were summarized as mean \pm standard deviation or median (interquartile range) for continuous variables and as frequency and percentages for categorical variables. Because of sparseness in some categories, the Fisher exact test was used to test for association of categorical variables. The Cochran-MantelHaenszel test was used to assess for trends in the HDSS score. Repeated-measures analysis of variance (ANOVA) was used to analyze the seasonal effect on sweating as subjects provided responses for each of the four seasons. An alpha of 0.05 was used to determine significance.

\section{RESULTS}

There were 140 responders to the survey. Surveys with either missing HDSS data $(n=2)$ or absence of a major lower-limb amputation $(n=10)$ were excluded. An additional 7 subjects who reported an upper-limb amputation were excluded. Of the 140 responders, 121 subjects were included in the final data analysis. The average age of participants was $57.5 \mathrm{yr}$ (range 23-87 yr), with the majority having a transtibial amputation. All subjects were at least 6 mo removed from their amputation surgery. Please refer to Table 2 for a descriptive summary of participants.

Scores on the HDSS were as follows: 1 (never noticeable and never interferes with ADLs) $=32.8$ percent, 2 (tolerable but sometimes interferes with ADLs) = 54.6 percent, 3 (barely tolerable and frequently interferes with ADLs) $=6.7$ percent, and 4 (intolerable and always interferes with ADLs) $=5.9$ percent. Nearly 13 percent of subjects reported severe hyperhidrosis (HDSS score of 3 or 4), while an additional 55 percent reported sweating to at least be a mild problem. When the burden of sweating was queried specifically as it relates to prosthetic fit and function on a 5-point Likert scale, subjects' responses correlated strongly with HDSS scores. Specifically, the Spearman correlation between HDSS and interference with prosthetic fit was $0.726, p<0.001$, and with prosthetic function was $0.804, p<0.001$. See the Figure for illustrative purposes. Regarding situations during which sweating is a problem, 66 percent reported during warm weather, 49 percent during vigorous activity, and 23 percent all the time. There was no significant associa-
Table 2.

Descriptive summary of participants.

\begin{tabular}{lc}
\hline & Result \\
\hline Age $($ yr), Mean \pm SD (Range) & $57.5 \pm 14.9(23-87)$ \\
Sex, $n(\%)$ & $10(8.3)$ \\
NR & $27(22.3)$ \\
Female & $84(69.4)$ \\
Male & \\
Level of Amputation, $n(\%)$ & $35(28.9)$ \\
Above Knee & $86(71.1)$ \\
Below Knee & \\
Cause of Amputation, $n(\%)$ & $12(9.9)$ \\
NR & $25(20.7)$ \\
Diabetes & $13(10.7)$ \\
Vascular & $37(30.6)$ \\
Trauma & $19(15.7)$ \\
Infection & $15(12.4)$ \\
Other & \\
HDSS Score, $n(\%)$ & $39(32.8)$ \\
1 & $65(54.6)$ \\
2 & $8(6.7)$ \\
4 & $7(5.9)$ \\
\end{tabular}

*See Table 1.

HDSS $=$ Hyperhidrosis Disease Severity Scale, NR $=$ no response given on returned survey, $\mathrm{SD}=$ standard deviation.

tion between sweating severity and reported length of daily prosthetic use.

Using the Fisher exact test, there was no significant association between HDSS and time since amputation or between HDSS and self-rated scores on the LCI-5. However, there was a significant association between level of amputation and sweating: 50 percent of those with a transfemoral amputation reported no problems with sweating. This association was significant by Fisher exact test and remained significant even after controlling for etiology of amputation and age, with an odds ratio of 0.35 (95\% confidence interval: $0.14-0.89$ ), $p=0.03$.

Regarding the association between etiology of amputation and sweating, the Cochran-Mantel-Haenszel test was used to test for trends in the HDSS score. When trauma was compared with all other causes of amputation, there was a trend toward higher HDSS scores in participants with traumatic amputation $(p=0.04)$. However, after controlling for age, this association did not reach 
(a)

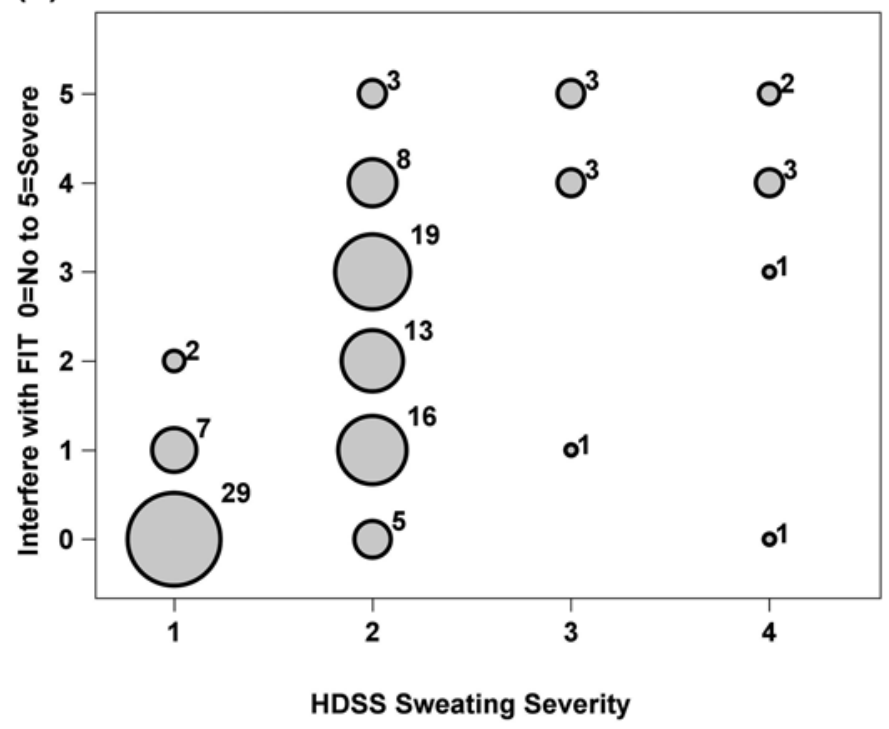

(b)

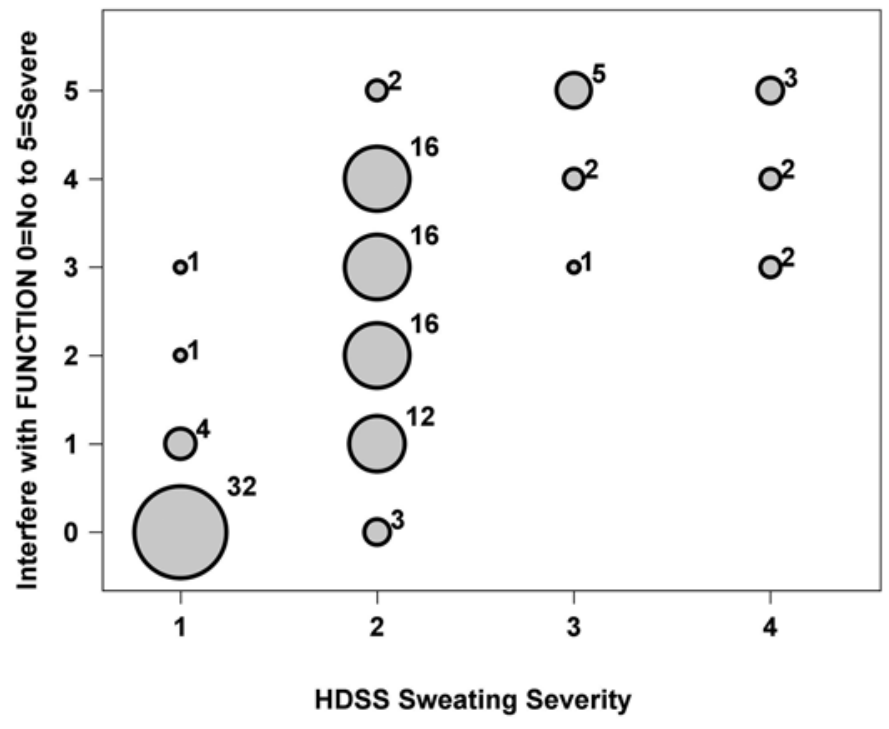

Figure.

Hyperhidrosis Disease Severity Scale (HDSS) sweating severity. Bubble plot showing correlation of HDSS scores to questions of hyperhidrosis impact on prosthesis (a) fit (Spearman correlation $=0.726, p<0.001$ ) and (b) function (Spearman correlation $=0.804, p<0.001)$. Along $x$-axis, HDSS scores are represented; along $y$-axis, subject responses to question, "How much does sweating of your residual limb interfere with your prosthesis (a) fitting or (b) functioning?" scored on 0-5 Likert scale. Bubble size is proportional to number of subjects at that level (also represented by number next to each bubble). statistical significance. No other trends existed for other causes of amputation.

Age appears to have a significant association with sweating. Subjects were grouped above and below the median age of $59 \mathrm{yr}$. Of those aged 60 and older, 47 percent reported no problems with sweating (HDSS score of 1 ), while only 19 percent of those under age 60 reported no problems with sweating. Looked at a different way, 3.6 percent of patients aged 60 and older reported severe problems with sweating (HDSS score of 3 or 4), while 19.7 percent of those under age 60 reported severe problems with sweating. Using the Cochran-Mantel-Haenszel test of trend, subjects under $60 \mathrm{yr}$ reported significantly higher HDSS scores $(p<0.001)$.

Not surprisingly, the participants with amputation reported a significantly higher burden of sweating during warmer seasons. With sweating treated as a continuous variable and use of a repeated-measures ANOVA, all seasons were significantly different from one other (the warmer season being comparatively more burdensome) with the exception of fall compared with spring (Table 3). Interestingly, even in winter, 49 percent of subjects report sweating to be at least a mild problem (score of $\geq 1$ on a 0-5 scale), with nearly 20 percent reporting it to be a moderate to severe problem (score of $\geq 3$ on a $0-5$ scale) (Table 4).

Subjects were also asked about a variety of possible interventions for sweating. Indeed, multiple interventions were reported for the treatment of hyperhidrosis. The most commonly used interventions were antiperspirants (prescription and over-the-counter), followed by the use of an extra sock or sheath under the liner. A variety of other methods had been tried as well (Table 5), and 38 percent of subjects had not tried any intervention. Regarding the reported efficacy of these interventions, most were felt to be not at all helpful or only mildly helpful at least half the time. A relatively small minority reported significant relief with the interventions tried, and no interventions were superior to others. Refer to Table 5 for further details regarding the self-reported efficacy of these various interventions.

\section{DISCUSSION}

Prior reports have noted sweating to be a significant problem for people with amputation [8,10,24-25]. This project sought to further explore the burden of sweating 
Table 3.

Sweating comparison by season.

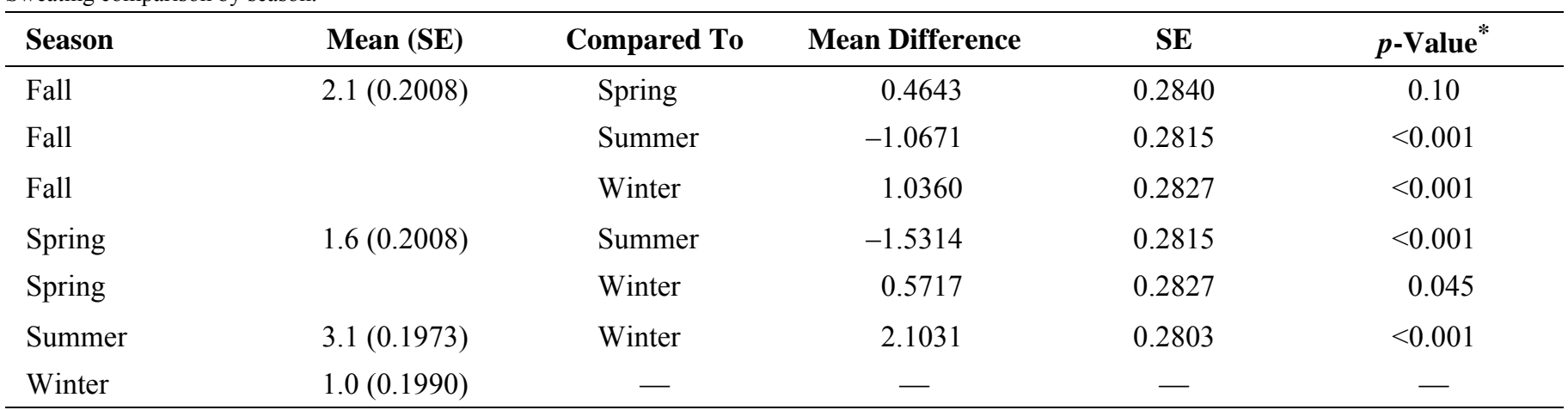

*Significance set at $p<0.05$.

$\mathrm{SE}=$ standard error.

Table 4.

Severity of sweating by season, distribution of response frequencies.

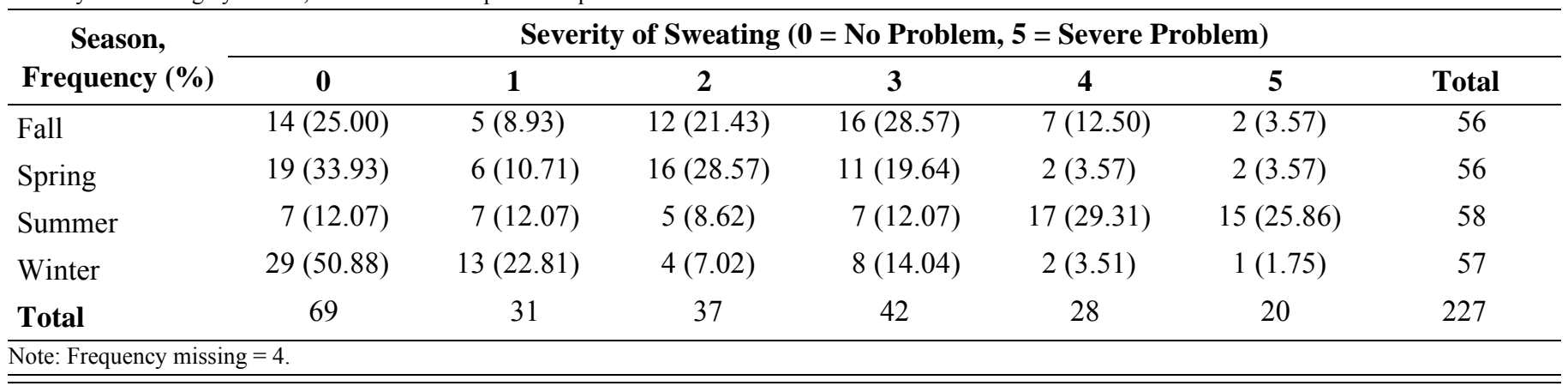

Table 5.

Perceived effectiveness of strategies to control sweating, all subjects.

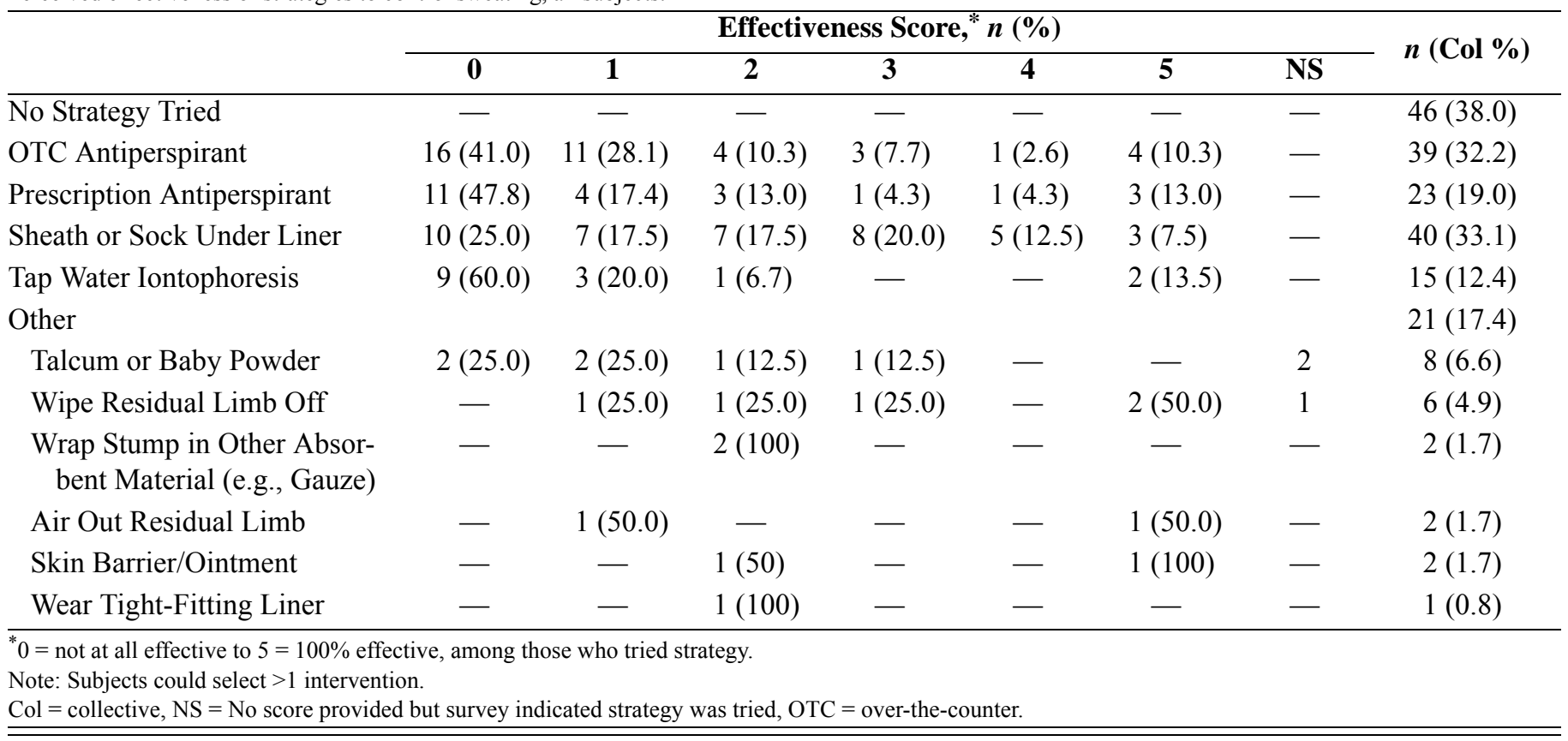


in people with amputation by identifying potential patient-specific factors associated with sweating and exploring relationships that may lead to greater problems with sweating, as well as learning what interventions are being used by patients to address this problem.

The HDSS was used in this study to quantify the incidence of clinically significant sweating. The HDSS is frequently used as a primary outcome measure in studies of hyperhidrosis in other locations, such as in axillary hyperhidrosis [26]. It is a recommended part of management algorithms for hyperhidrosis to guide clinicians in monitoring efficacy of interventions and even determining which management approaches may be most appropriate. It has previously been shown to correlate well with other quality of life measures, as well as actual measured sweat production [21]. The high correlations reported in this study between the HDSS and specific questions relating to prosthetic fit and function are important findings that validate the utility of the HDSS specifically in the amputee population. The HDSS should be regarded as an appropriate scale for measuring hyperhidrosis in people with amputation and should be included as an outcome measure in future studies. Further, it is an easy-to-use scale in clinic settings for screening for significant hyperhidrosis and for monitoring response to interventions.

This study lends further support to the fact that sweating is a common problem in people with amputation. It is more than a mere nuisance: 66 percent of subjects reported it to at least be a mild problem that interferes with optimal prosthetic fit and function, scoring $\geq 2$ on the HDSS. An HDSS score of 2 is an indication to begin treatment according to published hyperhidrosis guidelines [21]. A smaller but significant 13 percent of subjects reported it to be a severe problem, for which more aggressive management may be appropriate.

A few significant factors were associated with more severe sweating. First, younger age was predictive of more severe sweating. In this study, patients who were below the median age of the total group (60 yr) were more likely to have clinically significant sweating (i.e., an HDSS score of $\geq 2$ ). This association may reflect a greater level of activity in the younger age group or, perhaps, a natural physiologic effect to sweat less with advanced age. The observation that older individuals sweat less is not new; an epidemiologic study in 2004 showed the prevalence of sweating in the general population to be 1.7 percent in individuals older than $65 \mathrm{yr}$, but
3.5-4.5 percent in adults younger than $65 \mathrm{yr}$, a significant difference [27].

People with transtibial amputation appear to be significantly more affected by sweating than people with transfemoral amputation. The significance of this association is uncertain. Other variables were controlled for, such as amputation etiology, age, and reported daily use of a prosthesis. Sweat gland density does not appear to vary significantly from the leg region to the thigh region [28], so this finding may simply relate to the relative area of skin covered by liners and sleeves. Many patients with transtibial amputation utilize suction suspension, which necessitates the use of an outer sleeve, often going up to the midthigh to achieve an adequate seal. The relative surface area that is covered by prosthetic material, therefore, could be greater in people with transtibial amputation. This survey did not, however, query the type of suspension used, so this is purely speculative. Alternatively, this finding may be related to the relative activity levels of people with transtibial versus transfemoral amputation. While the LCI-5 was used in this survey to indicate the mobility capabilities of subjects, this instrument does not directly measure activity levels. It is certainly possible that people with transtibial amputation are more active and hence experience more sweating. This specific issue was not addressed in the survey.

People with traumatic amputation, in contrast to all other etiologies, appeared to also have significantly more sweating. However, after controlling for age, this association lost significance. Time since amputation was not a significant predictor of sweating. This finding demonstrates that clinicians should not assume that excessive residual-limb sweating will simply reduce over time as the individual accommodates to wearing a prosthesis. Indeed, Berke et al. surveyed both veterans and servicemembers from the Vietnam and Operation Iraqi Freedom/ Operation Enduring Freedom conflicts and found very similar rates between the two groups who reported being bothered by sweating inside their prosthetic sockets [9].

The effect of weather is somewhat revealing. It is not surprising that subjects reported significantly more troublesome sweating in warmer seasons. It is worth noting, however, that a substantial percentage of patients reported sweating to be a noticeable issue during winter. In fact, 49 percent of the sample reported it to be at least a mild issue and 20 percent of the sample reported it to be a moderate to severe issue. It is important, therefore, for 
clinicians to always ask their patients whether residuallimb hyperhidrosis is an issue, regardless of the season.

When looking more closely at functional mobility of people with lower-limb amputation, the LCI-5 scores and sweating severity did not show any significant association. There was a trend for those in the most severe sweating groups to have lower LCI-5 score distribution, but this was not significant. Nevertheless, this lack of association reveals an important point. One might assume that an individual with less functional mobility independence (i.e., a lower LCI-5 score) would be less active and therefore have less of a problem with sweating. This does not appear to be the case. Rather, these data suggest that persons with low or high LCI-5 scores are equally likely to be affected by excessive sweating.

There are a few interesting observations to make from the data collected on interventions that patients try. While the problem of sweating is clearly impactful for many patients, 38 percent of all subjects choose not to do anything about it. In fact, of those who indicated they have tried nothing for sweating, 54 percent of these scored $\geq 2$ on the HDSS, indicating that sweating interferes with daily activities. This may be due to a lack of perceived efficacy if interventions were tried unsuccessfully in the past but not reflected in the data collected or perhaps due to patients' lack of awareness of any available treatment options. Lastly, it may reflect poorly on healthcare providers, who may not be inquiring about this issue and therefore not educating patients about potential interventions.

It is clear that patients employ a variety of strategies in attempts to control sweating with varying levels of success. The most commonly used method, prescription or over-the-counter antiperspirants, was felt to be completely ineffective nearly 50 percent of the time and completely effective only 10-13 percent of the time. Wearing a sock or sheath under a liner was the next most frequently employed strategy, with a lower failure rate of 25 percent, but still a completely effective rate of only 7.5 percent. Conclusions as to the true superiority of one method over another cannot be drawn because these data were collected in an uncontrolled, retrospective fashion; but, these findings do support the notion that no single intervention is universally effective. Perhaps a combination of strategies needs to be employed to achieve the best patient outcome.

The results of this study may be helpful in guiding future research on the treatment of hyperhidrosis in peo- ple with amputation. At this time, there is a lack of published data on this population to guide treatment decisions. In the dermatologic literature, topical aluminum chloride is generally regarded as first-line treatment, but there are no data regarding its efficacy in patients with amputation [21]. Topical methenamine has been reported to be effective in amputee hyperhidrosis [29]. There are no convincing data that certain liner types are superior to others as it relates to sweat control [30]. Botulinum toxin is regarded as an important management option in other forms of hyperhidrosis [21], and there are a few case reports and small case series that highlight botulinum toxin as a possible treatment in people with amputation [13,19-20,31]. It may be possible for patients to be treated only once per year, given this study's finding that sweating is most burdensome in the warmer months and the long duration of action of botulinum toxin for hyperhidrosis (up to $200 \mathrm{~d}$ in one large trial of botulinum toxin A in axillary hyperhidrosis [32]). However, the large surface area encompassed by the prosthetic socket and other materials may make routine use of botulinum toxin tedious and impractical. It is not currently known whether sweat production in people with amputation is uniform and global over the residual limb or whether it is a more focal issue. In other forms of regional hyperhidrosis, smaller focal areas are commonly the primary sweat producers and can easily be identified using the Iodine-Starch test [21]; however, it is not known whether this test is feasible in people with amputation. This is an area that has not been well studied, and further research will be beneficial in providing clinicians a clear evidence base for management decisions.

Though perhaps limited by small sample size, the data obtained in this study are consistent with prior publications regarding the incidence of hyperhidrosis. While the majority of the studies published to date have focused on general skin complaints (including hyperhidrosis), this is the first study of its kind to collect data focused solely on issues with hyperhidrosis in people with amputation.

There are limitations to this study given that it is a convenience sample. There may be a possible retrospective bias due to some seasonal variation within the time at which the survey was collected, because the majority of the surveys were collected in the summer months. Given that the survey was mailed in most instances, data are occasionally missing for various questions. Further, the degree to which participants may have misread or misunderstood certain questions is unknown, though the instrument was 
scrutinized for readability and ease of understanding. Study participants were confined to a single geographic area. It is unknown whether patients living in other areas or more humid climates would experience more or less sweating. Though climate effect on hyperhidrosis was beyond the scope of this study, further research on the subject may aid clinicians in addressing this issue. Regardless of these limitations and the need for further research, this study supports the use of the HDSS as a viable tool for appropriately measuring sweating in people with amputation and assessing their need for treatment.

Subjects were not asked how various prosthetic systems (i.e., suspension method or liner material) had affected them or whether they had specifically accepted or rejected certain prosthetic components because of their influence on sweating. Some existing data suggest that differing suspension systems and liner materials may have an effect on sweating complaints [16,30], and collecting this information could have provided important additional insights into the problem. Further, subjects were not asked to identify whether they were utilizing new liner materials or suspension systems. This may be relevant, because other reports suggest wearing materials that are new to the subject's skin may produce a temporary increase in the sweating burden [14]. While acknowledging this limitation, it was not felt that this information could be reliably gathered in a mailed survey, because many patients may not know the specific materials their prosthetic components are made from.

People with upper-limb amputation were not included in this analysis because of a paucity of patients in the sample with an upper-limb amputation [7]; it was felt that numbers were insufficient to draw conclusions with any degree of confidence. Sweating may also be significant for this population and important to address to optimize prosthetic fit and function, particularly if patients use myoelectric devices [33].

\section{CONCLUSIONS}

In conclusion, hyperhidrosis is a common problem in this group of patients with lower-limb amputation and is associated with poor prosthetic fit and function. The HDSS appears to be a valid instrument to measure the burden of sweating in people with amputation. For people with lower-limb amputation, transtibial amputations and age (under $60 \mathrm{yr}$ old) appear to be statistically signif- icant patient-specific risk factors for hyperhidrosis. While sweating is more burdensome in warmer months, it is still frequently a problem in winter. There is no association between sweating severity and functional mobility as measured by the LCI-5, time since amputation, duration of daily prosthetic use, or etiology of amputation. Many interventions are tried by patients, albeit with variable and often no success. These results should inform clinicians of the substantial burden that hyperhidrosis plays in the lives of their patients with amputation. Although generalizations to the entire amputee population cannot positively be made from these results, these findings do confirm and augment current research and indicate the usefulness of the HDSS as a viable tool for measuring patients' hyperhidrosis and assessing treatment needs. Further research is required to provide evidence based guidelines for the management of this condition.

\section{ACKNOWLEDGMENTS}

\section{Author Contributions:}

Study concept and design: C. Hansen, B. Godfrey, M. McFadden. Analysis and interpretation of data: C. Hansen, B. Godfrey, J. Wixom, M. McFadden.

Drafting of manuscript: C. Hansen, B. Godfrey, J. Wixom.

Critical revision of manuscript for important intellectual content:

C. Hansen, B. Godfrey, J. Wixom, M. McFadden.

Financial Disclosures: The authors have declared that no competing interests exist.

Funding/Support: This material was based on work supported in part by Otto Bock Healthcare. There were no financial benefits to any of the authors.

Additional Contributions: Dr. Wixom is now with Physical Medicine And Rehabilitation, Intermountain Medical Center, Murray, Utah. Institutional Review: The institutional review boards at the University of Utah and Department of Veterans Affairs Salt Lake City Health Care System approved the protocol, and written informed consent was obtained from all patients participating in the study.

Participant Follow-Up: The authors do not plan to notify participants of the publication of this article because study data has been de-identified. Disclaimer: A small portion of this study, including partial preliminary results, was presented as part of a poster presentation at the American Academy of Physical Medicine and Rehabilitation Assembly in 2012: "Hyperhidrosis in amputee populations: Self-reported incidence, and impact on prosthetic fit and function" by Jody Wixom, MD; Molly McFadden, MS; Bradeigh Godfrey, DO; and Colby Hansen, MD. 


\section{REFERENCES}

1. Ziegler-Graham K, MacKenzie EJ, Ephraim PL, Travison TG, Brookmeyer R. Estimating the prevalence of limb loss in the United States: 2005 to 2050. Arch Phys Med Rehabil. 2008;89(3):422-29. [PMID:18295618] http://dx.doi.org/10.1016/j.apmr.2007.11.005

2. Akarsu S, Tekin L, Safaz I, Göktepe AS, Yazicioğlu K. Quality of life and functionality after lower limb amputations: Comparison between uni- vs. bilateral amputee patients. Prosthet Orthot Int. 2013;37(1):9-13.

[PMID:22833517] http://dx.doi.org/10.1177/0309364612438795

3. Zidarov D, Swaine B, Gauthier-Gagnon C. Quality of life of persons with lower-limb amputation during rehabilitation and at 3-month follow-up. Arch Phys Med Rehabil. 2009;90(4):634-45. [PMID:19345780]

http://dx.doi.org/10.1016/j.apmr.2008.11.003

4. Asano M, Rushton P, Miller WC, Deathe BA. Predictors of quality of life among individuals who have a lower limb amputation. Prosthet Orthot Int. 2008;32(2):231-43. [PMID:18569891] http://dx.doi.org/10.1080/03093640802024955

5. Meulenbelt HE, Geertzen JH, Jonkman MF, Dijkstra PU. Skin problems of the stump in lower limb amputees: 1. A clinical study. Acta Derm Venereol. 2011;91(2):173-77. [PMID:21290085]

6. Meulenbelt HE, Geertzen JH, Jonkman MF, Dijkstra PU. Skin problems of the stump in lower-limb amputees: 2. Influence on functioning in daily life. Acta Derm Venereol. 2011;91(2):178-82. [PMID:21279299]

7. Almassi F, Emadi N, Mousavi B, Masumi M, Souroush MR. Dermatosis contributing factors in bilateral lower limb war-amputees. PJBS. 2010;13(2):78-82.

[PMID:20415141] http://dx.doi.org/10.3923/pjbs.2010.78.82

8. Meulenbelt HE, Geertzen JH, Jonkman MF, Dijkstra PU. Determinants of skin problems of the stump in lower-limb amputees. Arch Phys Med Rehabil. 2009;90(1):74-81. [PMID:19154832] http://dx.doi.org/10.1016/j.apmr.2008.07.015

9. Berke GM, Fergason J, Milani JR, Hattingh J, McDowell M, Nguyen V, Reiber GE. Comparison of satisfaction with current prosthetic care in veterans and servicemembers from Vietnam and OIF/OEF conflicts with major traumatic limb loss. J Rehabil Res Dev. 2010;47(4):361-71.

[PMID:20803404]

http://dx.doi.org/10.1682/JRRD.2009.12.0193

10. Hagberg K, Brånemark R. Consequences of non-vascular trans-femoral amputation: A survey of quality of life, prosthetic use and problems. Prosthet Orthot Int.
2001;25(3):186-94. [PMID:11860092]

http://dx.doi.org/10.1080/03093640108726601

11. Burger H, Marincek C. Upper limb prosthetic use in Slovenia. Prosthet Orthot Int. 1994;18(1):25-33.

[PMID:8084746]

12. Levy SW. Amputees: Skin problems and prostheses. Cutis. 1995;55(5):297-301. [PMID:7614842]

13. Wollina U, Konrad H, Graefe T, Thiele J. Botulinum toxin A for focal hyperhidrosis in leg amputees: A case report. Acta Derm Venereol. 2000;80(3):226-27. [PMID:10954228] http://dx.doi.org/10.1080/000155500750043140

14. Datta D, Vaidya SK, Howitt J, Gopalan L. Outcome of fitting an ICEROSS prosthesis: Views of trans-tibial amputees. Prosthet Orthot Int. 1996;20(2):111-15. [PMID:8876004]

15. Hachisuka K, Dozono K, Ogata H, Ohmine S, Shitama H, Shinkoda K. Total surface bearing below-knee prosthesis: Advantages, disadvantages, and clinical implications. Arch Phys Med Rehabil. 1998;79(7):783-89. [PMID:9685091] http://dx.doi.org/10.1016/S0003-9993(98)90356-2

16. Gholizadeh H, Abu Osman NA, Eshraghi A, Ali S, Yahyavi ES. Satisfaction and problems experienced with transfemoral suspension systems: A comparison between common suction socket and seal-in liner. Arch Phys Med Rehabil. 2013;94(8):1584-89. [PMID:23262380] http://dx.doi.org/10.1016/j.apmr.2012.12.007

17. Cluitmans J, Geboers M, Deckers J, Rings F. Experiences with respect to the ICEROSS system for trans-tibial prostheses. Prosthet Orthot Int. 1994;18(2):78-83.

[PMID:7991364]

18. Hachisuka K, Nakamura T, Ohmine S, Shitama $H$, Shinkoda K. Hygiene problems of residual limb and silicone liners in transtibial amputees wearing the total surface bearing socket. Arch Phys Med Rehabil. 2001;82(9):128690. [PMID:11552206] http://dx.doi.org/10.1053/apmr.2001.25154

19. Charrow A, DiFazio M, Foster L, Pasquina PF, Tsao JW. Intradermal botulinum toxin type A injection effectively reduces residual limb hyperhidrosis in amputees: A case series. Arch Phys Med Rehabil. 2008;89(7):1407-9. [PMID:18586144] http://dx.doi.org/10.1016/j.apmr.2007.11.054

20. Kern U, Kohl M, Seifert U, Schlereth T. Botulinum toxin type B in the treatment of residual limb hyperhidrosis for lower limb amputees: A pilot study. Am J Phys Med Rehabil. 2011;90(4):321-29. [PMID:21765248] http://dx.doi.org/10.1097/PHM.0b013e31820636fd

21. Solish N, Bertucci V, Dansereau A, Hong HC, Lynde C, Lupin M, Smith KC, Storwick G; Canadian Hyperhidrosis Advisory Committee. A comprehensive approach to the recognition, diagnosis, and severity-based treatment of 
focal hyperhidrosis: Recommendations of the Canadian Hyperhidrosis Advisory Committee. Dermatol Surg. 2007;33(8):908-23. [PMID:17661933]

22. Franchignoni F, Orlandini D, Ferriero G, Moscato TA. Reliability, validity, and responsiveness of the Locomotor Capabilities Index in adults with lower-limb amputation undergoing prosthetic training. Arch Phys Med Rehabil. 2004;85(5):743-48. [PMID:15129398] http://dx.doi.org/10.1016/j.apmr.2003.06.010

23. Franchignoni F, Giordano A, Ferriero G, Muñoz S, Orlandini D, Amoresano A. Rasch analysis of the Locomotor Capabilities Index-5 in people with lower limb amputation. Prosthet Orthot Int. 2007;31(4):394-404.

[PMID:18050010]

http://dx.doi.org/10.1080/03093640701253952

24. Meulenbelt HE, Geertzen JH, Dijkstra PU, Jonkman MF. Skin problems in lower limb amputees: An overview by case reports. J Eur Acad Dermatol Venereol. 2007;21(2): 147-55. [PMID:17243947] http://dx.doi.org/10.1111/j.1468-3083.2006.01936.x

25. Davidson J. A survey of the satisfaction of upper limb amputees with their prostheses, their lifestyles, and their abilities. J Hand Ther. 2002;15(1):62-70.

[PMID:11866354] http://dx.doi.org/10.1053/hanthe.2002.v15.01562

26. Solish N, Benohanian A, Kowalski JW; Canadian Dermatology Study Group on Health-Related Quality of Life in Primary Axillary Hyperhidrosis. Prospective open-label study of botulinum toxin type $\mathrm{A}$ in patients with axillary hyperhidrosis: Effects on functional impairment and quality of life. Dermatol Surg. 2005;31(4):405-13.

[PMID:15871315] http://dx.doi.org/10.1097/00042728-200504000-00006

27. Strutton DR, Kowalski JW, Glaser DA, Stang PE. US prevalence of hyperhidrosis and impact on individuals with axillary hyperhidrosis: Results from a national survey. $\mathrm{J}$ Am Acad Dermatol. 2004;51(2):241-48. [PMID:15280843] http://dx.doi.org/10.1016/j.jaad.2003.12.040

28. Taylor NA, Machado-Moreira CA. Regional variations in transepidermal water loss, eccrine sweat gland density, sweat secretion rates and electrolyte composition in resting and exercising humans. Extrem Physiol Med. 2013;2(1):4.

\section{[PMID:23849497]}

http://dx.doi.org/10.1186/2046-7648-2-4

29. Susak Z, Minkov R, Isakov E. The use of Methenamine as an antiperspirant for amputees. Prosthet Orthot Int. 1996;20(3):172-75. [PMID:8985996]

30. Ali S, Abu Osman NA, Naqshbandi MM, Eshraghi A, Kamyab M, Gholizadeh H. Qualitative study of prosthetic suspension systems on transtibial amputees' satisfaction and perceived problems with their prosthetic devices. Arch Phys Med Rehabil. 2012;93(11):1919-23. [PMID:22579945] http://dx.doi.org/10.1016/j.apmr.2012.04.024

31. García-Morales I, Pérez-Bernal A, Camacho F. Letter: Stump hyperhidrosis in a leg amputee: treatment with botulinum toxin A. Dermatol Surg. 2007;33(11):1401-2. [PMID:17958602]

32. Lowe NJ, Glaser DA, Eadie N, Daggett S, Kowalski JW, Lai PY; North American Botox in Primary Axillary Hyperhidrosis Clinical Study Group. Botulinum toxin type A in the treatment of primary axillary hyperhidrosis: A 52-week multicenter double-blind, randomized, placebo-controlled study of efficacy and safety. J Am Acad Dermatol. 2007;56(4):604-11. [PMID:17306417] http://dx.doi.org/10.1016/j.jaad.2007.01.009

33. Sauter WF, Naumann S, Milner M. A three-quarter type below-elbow socket for myoelectric prostheses. Prosthet Orthot Int. 1986;10(2):79-82. [PMID:3774515]

Submitted for publication April 17, 2014. Accepted in revised form November 10, 2014.

This article and any supplementary material should be cited as follows:

Hansen C, Godfrey B, Wixom J, McFadden M. Incidence, severity, and impact of hyperhidrosis in people with lower-limb amputation. J Rehabil Res Dev. 2015;52(1):31-40.

http://dx.doi.org/10.1682/JRRD.2014.04.0108

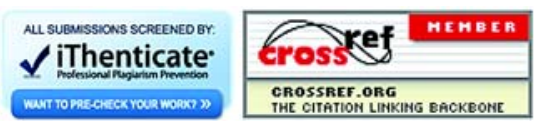

